industry that thrives on the mismanagement of health waste.

Ragpickers - the name given to poor people who recycle trash for a profit sell used syringes for US12-cents a kilo to companies that repackage them and make them look like they've never been used, Koska says.

Syringe manufacturers and health practitioners say the increased cost of auto-disposable syringes is a barrier to use, but Koska says the 2.5-rupee (6cent) price tag isn't prohibitive and doesn't wholly explain the willingness to use unsafe needles.

"It's incompetent supply lines. It's bad stocking. It's just a continual atmosphere of reuse, where they believe that everything has a second life," Koska says. "There's only so much you can do, and you can push and push and push. What I don't want to do is try and be a nanny to India. I think we provided some good stimulus and this is really the last phase of that campaign."

As he walks through the Okhla slum,
Safe Point official Atul Sharma says the average unlicensed practitioner wouldn't publicly admit to reusing syringes.

Along the slum's main drag, a handful of storefront medical centres - each the size of a modest walk-in closet - are crowded among the barber stalls and candy shops. Each kiosk typically features a professionally dressed quack equipped with a stethescope, a vial atop his desk and a wall of over-the-counter medications.

After years in the business, they have often a measure of local trust, says Sharma.

But the combination of used syringes and unlicensed medical practitioners can be lethal, he adds.

Passing a dumpsite littered with opened packages that once contained syringes, Sharma urges caution, although no needles are immediately evident within the trash. - Natalie Alcoba, New Delhi, India

DOI:10.1503/cmaj.090927

\title{
More news at www.cmaj.ca
}

Drug ads: CanWest Mediaworks Inc. has requested an adjournment of its Canadian Charter of Rights and Freedoms challenge to the ban on direct-toconsumer advertising. - Ann Silversides, CMAJ

Healing stories: Hamilton, Ontario therapist uses story-based curriculum to treat post-traumatic stress disorder in Afghanistan. - Laura Eggertson, CMAJ
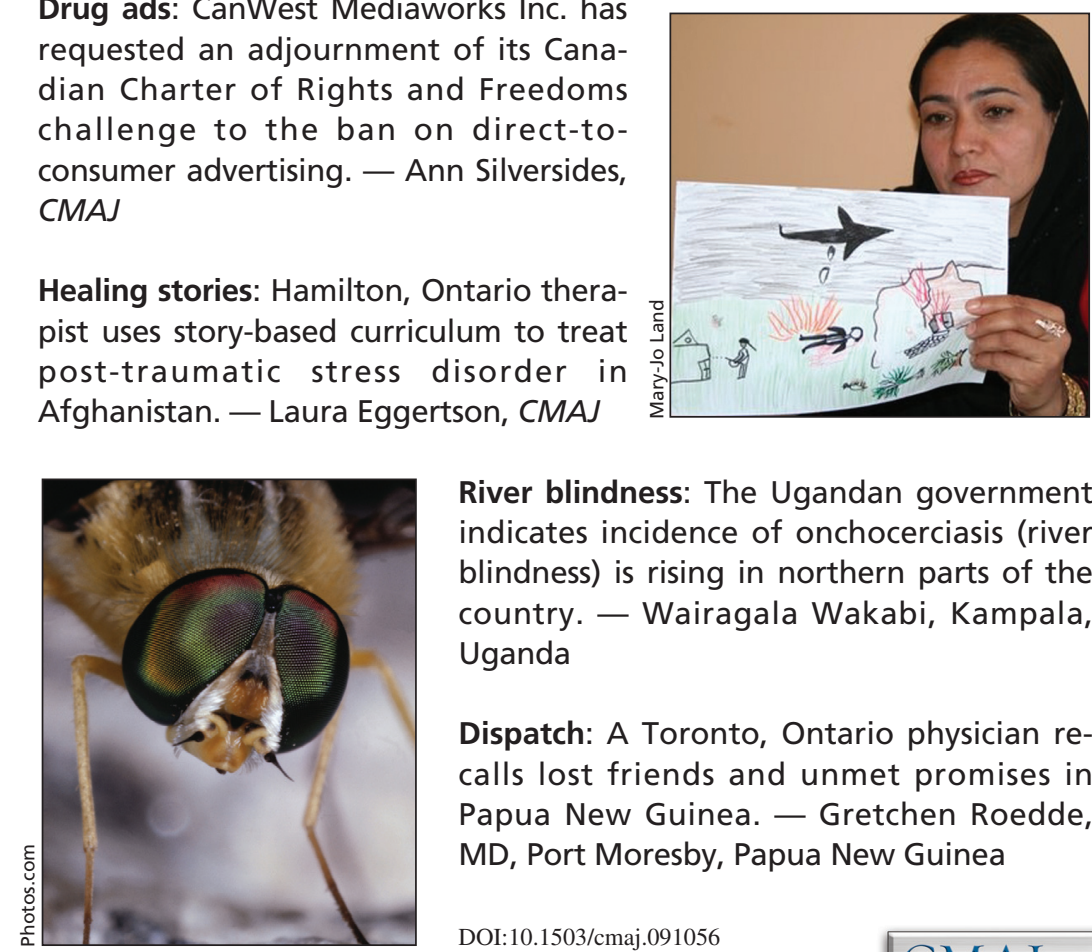

River blindness: The Ugandan government indicates incidence of onchocerciasis (river blindness) is rising in northern parts of the country. - Wairagala Wakabi, Kampala, Uganda

Dispatch: A Toronto, Ontario physician recalls lost friends and unmet promises in Papua New Guinea. - Gretchen Roedde, MD, Port Moresby, Papua New Guinea

DOI:10.1503/cmaj.091056 